\title{
Prognostic Factors after Curative Resection of Pancreatic Ductal Adenocarcinoma: a Retrospective Study
}

\author{
Zane Simtniece ${ }^{1}$, Ilze Strumfa ${ }^{1 *}$, Arnis Abolins ${ }^{1}$, Andrejs Vanags ${ }^{2}$ and Janis Gardovskis ${ }^{2}$ \\ Correspondence: ilze.strumfa@rsu.lv \\ ${ }^{1}$ Department of Pathology, Riga Stradins University, Dzirciema Street 16, Riga, Latvia. \\ ${ }^{2}$ Department of Surgery, Riga Stradins University, Dzirciema Street 16, Riga, Latvia.
}

\begin{abstract}
Background: Pancreatic ductal adenocarcinoma (PDAC) is one of the most aggressive tumours with dismal prognosis. Although curative resection with adjuvant chemoradiotherapy is the most effective treatment, the surgery is frequently limited by cancer spread or poor general status of the patient. Relatively few studies have analysed the outcomes of surgically treated pancreatic cancer. Controversies exist about several biological markers that could be important in the era of personalized medicine. Thus, the aim of our study was to determine frequency and extent of expression of biological markers (Ki-67, p53, Bcl-2, vimentin, CD44) in relation to survival after potentially curative radical surgical treatment of PDAC.

Methods: The study was designed as retrospective, protocol-based evaluation of 63 consecutive pancreatic ductal adenocarcinoma cases. Ki-67, p53, Bcl-2, vimentin and CD44 expression was evaluated by immunohistochemistry. The survival was assessed by Kaplan-Meier method. Spearman's rank correlation, t-test and Kruskal-Wallis test, log-rank and Cox regression analysis were used for appropriate statistical analysis. The study was approved by Committee of Ethics. Results: Patients' mean age was 63.2 years. The mean survival was 19.5 month $(95 \%$ confidence interval $(\mathrm{CI})=11.3-27.8)$. The tumours were mostly T3-4 (95.2\%; 95\% CI = 86.7-98.2) and larger than $2 \mathrm{~cm}(90.9 \%$; 95\% CI = 78.8-96.3). Metastases in lymph nodes were identified in $67.2 \%(95 \% \mathrm{CI}=54.7-77.7)$ cases. The most frequent tumour stage was IIB $(62.3 \%$; $95 \%$ $\mathrm{CI}=49.7-73.4)$. Resection margins were involved in 51.7\% (95\% CI = 39.1-64.1) cases. Perineural and intraneural invasion was found in $84.1 \%$ (95\% CI $=73.1-91.1)$ of patients. Correlation was found between survival and high histologic grade ( $\mathrm{p}$ $=0.017)$, resection margin involvement $(\mathrm{p}=0.039)$, high Ki-67 $(\mathrm{p}=0.022)$ and vimentin positivity $(\mathrm{p}=0.023)$, as well as between CD44 expression and $\mathrm{N}$ stage $(\mathrm{p}=0.022)$ and Ki-67 $(\mathrm{p}=0.010)$. There was a trend to correlation between CD44 and vimentin expression ( $\mathrm{p}=0.058)$ as well as between $\mathrm{p} 53$ expression and peri- and intraneural invasion $(\mathrm{p}=0.053)$. Conclusions: The survival after surgical resection of pancreatic carcinoma remains poor. The tumour grade, positive resection margins, proliferation fraction and epithelial-mesenchymal transition affect patients' survival. CD44 expression correlates with Ki-67 and N stage. Trend to correlation was observed between p53 expression and peri- and intraneural growth.
\end{abstract}

Keywords: pancreatic cancer, survival, immunohistochemistry, CD44, Ki-67, vimentin, p53

\section{Background}

Pancreatic ductal adenocarcinoma (PDAC) is an aggressive disease with a grave prognosis. In 2008 there were 277 000 new cases of pancreatic carcinoma, ranking it in the 13th place among all cancers excluding non-melanoma skin cancer. Pancreatic carcinoma was the 9th leading cause of cancer-related death worldwide [1]. Five- year survival rate of inoperable patients is $0.6-3.8 \%$ across all the PDAC stages, but in surgically treated patients it reaches around $5 \%[2,3]$. Better five year survival rates for surgically treated patients are represented in Bilimoria et al research (2.8-31.4\%), where all types of pancreatic adenocarcinomas were included [2]. Early diagnostics and surgery are the best options to improve patients' survival. However, lack of early specific symptoms and diagnostic markers result in frequent occurrence of widespread tumour invasion and presence of metastases at the time of PDAC diagnostics [4-8]. As surgical treatment is feasible only if distant metastases are absent, major blood vessels are not affected and the patients' general health status is acceptable, only $15-20 \%$ patients undergo curative surgical resection $[\mathbf{9}, \mathbf{1 0}]$. Chemotherapy alone cannot ensure survival improvement. Adjuvant chemoradiotherapy improves postoperative survival results [11]. In comparison

(c) 2012 Strumfa et al; licensee Herbert Publications Ltd. This is an open access article distributed under the terms of Creative Commons Attribution License (http://creativecommons.org/licenses/by/3.0),This permits unrestricted use, distribution, and reproduction in any medium, provided the original work is properly cited. 
to other malignant tumours, PDAC is characterised by almost the worst constellation of characteristics describing tumour spread and patients' survival. Active scientific research is devoted to the analysis of prognostic and predictive factors. Findings that are associated with significantly reduced survival, include large tumour size (above $3 \mathrm{~cm}$ ), metastasis in lymph nodes, positive resection margins, high histologic grade, intravascular invasion and marked

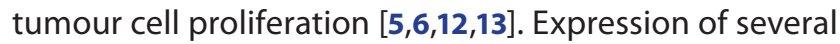
biological markers in tumour tissue is described as significant due to correlation with the progression of tumour and resistance to chemoradiotherapy. Relevant examples include S100 calcium-binding protein A4, human equilibrative nucleoside transporter 1 , vascular endothelial growth factor and low expression of insulin-like growth factor binding protein $7[6,14,15]$. Studies of several other markers have yielded contradictory results. These markers include tumour suppressor protein p53, mesenchymal cell intermediate filament vimentin, apoptosis regulator protein $\mathrm{Bcl}-2$ as well as CD44 - cell surface glycoprotein, which is involved in cell adhesion, migration, proliferation and apoptosis [14,16-20]. Thus, the aim of our study was to determine frequency and extent of expression of biological markers (Ki-67, p53, $\mathrm{BCl}-2$, vimentin, $\mathrm{CD} 44$ ) in relation to survival of patients after potentially radical surgical treatment of pancreatic carcinoma.

\section{Methods}

\section{Patients and Tissue Samples}

The study was performed as a retrospective investigation. Sixty three consecutive cases of potentially radically operated pancreatic ductal adenocarcinoma in the time interval from January 2004 to June 2012 were consecutively selected from the archive of single university hospital. No patients had received preoperative chemotherapy or radiotherapy.

The analysed factors were: patient's age, gender, type of surgery, tumour localization, tumour size by the largest diameter, tumour characteristics by TNM (T: size and local spread of primary tumour, N: status of regional lymph nodes regarding metastasis, M: presence or absence of distant metastasis) and stage, histological grade (high, moderate or (ow), status of resection margins, vascular and perivascular, perineural and intraneural invasion, as well as survival rate (SR). Tumours were classified according to the World Health Organization [21]. The TNM staging was performed in accordance with the Seventh Edition of the AJCC Cancer Staging Handbook [22]. In order to reach data consistency, the diagnostic pathology slides were reviewed by three independent pathologists (ZS, IS, AA). The clinical data were reviewed by an experienced surgeon (AV). The survival was defined as an interval between the date of surgery and the last follow-up or death due to pancreatic cancer. Censoring occurred if patients were alive at last follow-up or died due to other reasons.

\section{Immunohistochemistry}

Immunohistochemical (IHC) staining of formalin-fixed paraffin-embedded tumour tissue was performed using panel of primary antibodies (Table 1). In brief, 3-micrometrethick sections were cut on electrostatically charged glass slides (Histobond, Marienfeld, Germany) and subjected to deparaffinisation in graded alcohols and xylene. Heatinduced antigen retrieval was performed in microwave oven (3x5 min.) using basic TEG buffer ( $\mathrm{pH}$ 9.0). After blocking of endogenous peroxidase, the sections were incubated with primary antibodies at room temperature for $60 \mathrm{~min}$. The bound primary antibodies were detected by enzymeconjugated polymeric visualisation system EnVision linked with horseradish peroxidase. 3,3'-diaminobenzidine was used as chromogen, followed by counterstaining implying Meyer's hematoxylin. All IHC reagents were produced by Dako (Glostrup, Denmark). Positive and negative controls were performed and reacted appropriately.

\section{Evaluation of immunohistochemical staining}

The expression of all markers was evaluated in the appropriate subcellular compartment of the neoplastic cells.

Table 1. The applied panel of primary antibodies: characteristics of antibody and applied dilution

\begin{tabular}{|c|c|c|c|c|c|}
\hline Antigen & Antibody & Clone & Producer & Code & Dilution \\
\hline Ki-67 & $\begin{array}{l}\text { Monoclonal mouse anti-human } \mathrm{Ki}-67 \\
\text { antigen }\end{array}$ & MIB-1 & $\begin{array}{l}\text { Dako, Glostrup, } \\
\text { Denmark }\end{array}$ & M7240 & $1: 100$ \\
\hline p53 & Monoclonal mouse anti-human p53 protein & DO-7 & $\begin{array}{l}\text { Dako, Glostrup, } \\
\text { Denmark }\end{array}$ & M7001 & 1:400 \\
\hline $\mathrm{Bcl}-2$ & $\begin{array}{l}\text { Monoclonal mouse anti-human Bcl-2 } \\
\text { oncoprotein }\end{array}$ & 124 & $\begin{array}{l}\text { Dako, Glostrup, } \\
\text { Denmark }\end{array}$ & M0887 & $1: 800$ \\
\hline Vimentin & Monoclonal mouse anti-vimentin & V9 & $\begin{array}{l}\text { Dako, Glostrup, } \\
\text { Denmark }\end{array}$ & M0725 & $1: 200$ \\
\hline CD44 & $\begin{array}{l}\text { Monoclonal mouse anti-human CD } 44 \text {, } \\
\text { phagocytic glycoprotein-1 }\end{array}$ & DF1485 & $\begin{array}{l}\text { Dako, Glostrup, } \\
\text { Denmark }\end{array}$ & M7082 & $1: 50$ \\
\hline
\end{tabular}


Ki-67 and p53 expression were counted as positive if only nuclei of tumour cells were stained. $\mathrm{Bcl}-2$ and vimentin expression was evaluated in the cytoplasm and CD44 in the membrane of neoplastic cells. The expression was graded by intensity as 0 , negative; 1 , weak; 2 , moderate and 3 , intense. Only moderate or intense reactivity was considered positive. After intensity evaluation, positive tumour cells were counted among $\mathbf{5 0 0}$ malignant cells and expressed as the percentage.

\section{Statistical analysis}

The statistical analysis was performed using Statistical Package for the Social Sciences (SPSS, version 20). Data were expressed as mean \pm standard deviation (SD) or percentage. The $95 \%$ confidence interval $(\mathrm{Cl})$ was invariably calculated by Confidence Interval Analysis (CIA) software [23]. For survival analysis Kaplan - Meier method was used. Survival for positive versus negative IHC staining was compared with log-rank test. In multivariate analysis Cox regression analysis was used. Cox regression analysis was used to determine the relative impact of tumour stage, $\mathrm{T}$ (size and local invasion of primary tumour), G (histological grade), N (regional lymph nodes regarding metastasis), $\mathrm{R}$ (status of resection margins) parameters and positive versus negative IHC staining on survival. Correlation between SR and expression of the studied $\mathrm{IHC}$ markers (count of positive cells), tumour size and the mutual correlation of these parameters were analysed by Spearman's rank correlation. T-test was used to determine the correlation between morphological factors (tumour size, $\mathrm{N}$ stage, surgical resection margins, vascular and perivascular invasion, perineural and intraneural invasion) and SR as well as expression of $\mathrm{Ki}-67, \mathrm{p} 53, \mathrm{BCl}-2$, vimentin and CD44. Correlation between histologic grade and SR was evaluated by Kruskal-Wallis test. ANOVA was applied to determine correlation between pathologic stage and $\mathrm{SR}$. The $\mathrm{p}$-values of $\leq 0.05$ were considered statistically significant for all analyses.

\section{Ethical considerations}

The study was carried out in accordance with the Declaration of Helsinki and was approved by the Committee of Ethics, Riga Stradins University.

\section{Results \\ Clinical and morphological characteristics of the study group}

During the evaluated period (2004-2012), 63 patients underwent potentially curative resection of pancreatic carcinoma. The main clinical and morphological findings are summarized in Table 2. Patients' mean age was $63.2 \pm 10.8$ years (range $38-81 ; 95 \% \mathrm{Cl}=60.5-65.9$ ). Pancreatoduodenectomy was performed in 54/63 (85.71\%; $95 \% \mathrm{Cl}=75.0-92.2$ ) cases, distal pancreatectomy in 5/63
(7.9\%; $95 \% \mathrm{Cl}=3.5-17.3$ ) cases and total pancreatectomy in 4/63 (6.4\%; 95\% Cl = 2.6-15.2) cases. In addition, splenectomy was carried out in 5/63 (7.9\%; $95 \% \mathrm{Cl}=3.5-17.3)$ cases. The mean tumour size was $3.7 \pm 1.4 \mathrm{~cm}$ (range $1.5-9 ; 95 \% \mathrm{Cl}=3.2-$ 4.1). After evaluation of TNM parameters, tumour stage was following: IA in 1.6\% $(95 \% \mathrm{Cl}=0.4-8.7)$ cases, IB in 3.3\% $(95 \%$ $\mathrm{Cl}=1.0-11.1)$ cases, IIA in $26.2 \%(95 \% \mathrm{Cl}=16.8-38.5)$ cases, IIB in $62.8 \%(95 \% \mathrm{Cl}=49.7-73.4)$ cases, III in $1.6 \%(95 \% \mathrm{Cl}=$ $0.4-8.7)$ cases. In $4.9 \%(95 \% \mathrm{Cl}=1.8-13.5)$ cases, the tumour stage was IV due to the presence of liver metastases. As

Table 2. Clinical and morphological characteristics of the study group

\begin{tabular}{|c|c|c|c|}
\hline Parameters & $\begin{array}{l}\text { No. of } \\
\text { patients }\end{array}$ & $\begin{array}{l}\text { Percentage } \\
\text { of patients } \\
(\%)\end{array}$ & $\begin{array}{l}95 \% \\
\text { Confidence } \\
\text { Interval }\end{array}$ \\
\hline \multicolumn{4}{|l|}{ Age (years) } \\
\hline$\leq 60$ & 26 & 41.3 & $29.9-53.6$ \\
\hline$>60$ & 37 & 58.7 & $46.4-70.1$ \\
\hline \multicolumn{4}{|l|}{ Gender } \\
\hline Male & 30 & 47.6 & $35.8-59.8$ \\
\hline Female & 33 & 52.4 & $40.2-64.3$ \\
\hline \multicolumn{4}{|c|}{ Tumour localization } \\
\hline Pancreatic head & 54 & 85.7 & $75.0-92.2$ \\
\hline Other & 9 & 14.3 & $7.8-25.0$ \\
\hline \multicolumn{4}{|l|}{ Tumour size $(\mathrm{cm})$} \\
\hline$\leq 2$ & 4 & 9.1 & $3.7-21.2$ \\
\hline$>2$ & 40 & 90.9 & $78.8-96.3$ \\
\hline$\geq 3$ & 30 & 68.2 & $53.4-80.0$ \\
\hline \multicolumn{4}{|l|}{ T stage } \\
\hline $\mathrm{T} 1$ and $\mathrm{T} 2$ & 3 & 4.8 & $1.8-13.3$ \\
\hline $\mathrm{T} 3$ and $\mathrm{T} 4$ & 59 & 95.2 & $86.7-98.2$ \\
\hline \multicolumn{4}{|l|}{$\mathrm{N}$ stage } \\
\hline No & 20 & 32.8 & $22.3-45.3$ \\
\hline N1 & 41 & 67.2 & $54.7-77.7$ \\
\hline \multicolumn{4}{|l|}{ Tumour grade } \\
\hline Low & 8 & 12.7 & $6.6-23.2$ \\
\hline Moderate & 39 & 61.9 & $49.5-72.9$ \\
\hline High & 16 & 25.4 & $16.3-37.4$ \\
\hline \multicolumn{4}{|l|}{ Resection margins } \\
\hline Negative & 28 & 48.3 & $35.9-60.9$ \\
\hline Positive & 30 & 51.7 & $39.1-64.1$ \\
\hline \multicolumn{4}{|c|}{ Vascular and perivascular invasion } \\
\hline Absent & 41 & 65.1 & $52.7-75.7$ \\
\hline Present & 22 & 34.9 & $24.3-47.3$ \\
\hline \multicolumn{4}{|c|}{ Intraneural and perineural invasion } \\
\hline Absent & 10 & 15.9 & $8.9-26.9$ \\
\hline Present & 53 & 84.1 & $73.1-91.1$ \\
\hline
\end{tabular}

Abbreviations. T1, tumour limited to the pancreas, $2 \mathrm{~cm}$ or less in greatest dimension; $\mathrm{T} 2$, tumour limited to the pancreas, more than $2 \mathrm{~cm}$ in greatest dimension; T3, tumour extends beyond the pancreas but without involvement of the celiac axis or the superior mesenteric artery; T4, tumour involves the celiac axis or the superior mesenteric artery; N0, no regional lymph node metastasis; N1, regional lymph node metastasis [22]. 


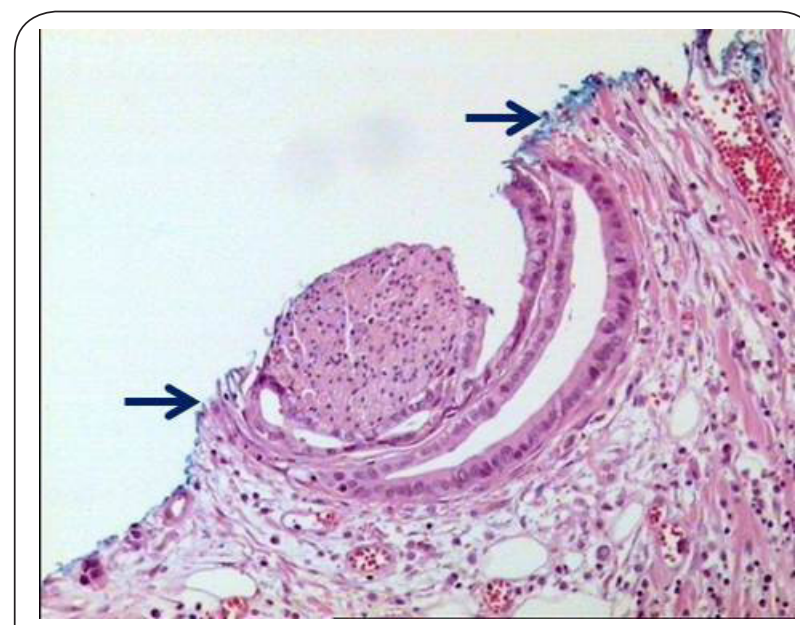

Figure 1. Pancreatic ductal adenocarcinoma. Note the perineural invasion and the subsequent spread to the inked surgical resection margin $(\rightarrow)$. Haematoxylin-eosin (HE), original magnification (OM) 100x.

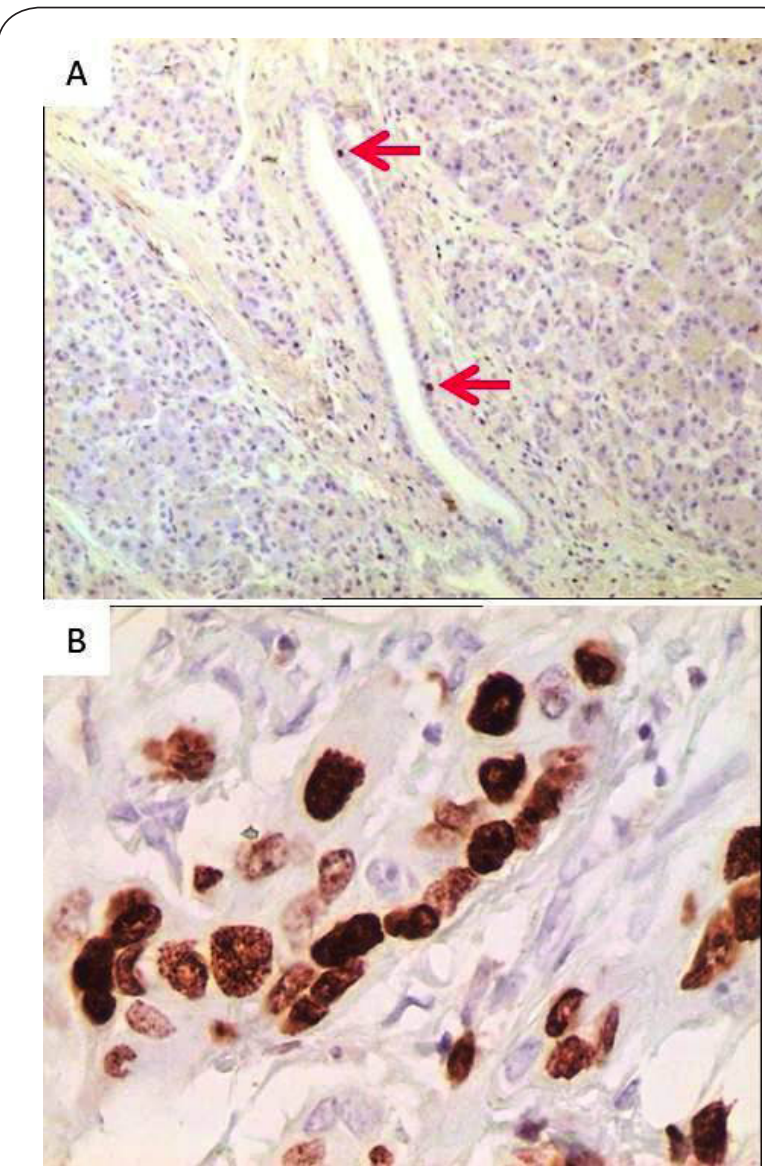

Figure 2. Immunohistochemical visualisation of Ki-67. (A) Nuclear expression of Ki-67 in few ductal epithelial cells of normal pancreas. Immunoperoxidase (IP), OM 100x. (B) Nuclear expression of Ki-67 in pancreatic ductal adenocarcinoma (PDAC). IP, OM 400x.

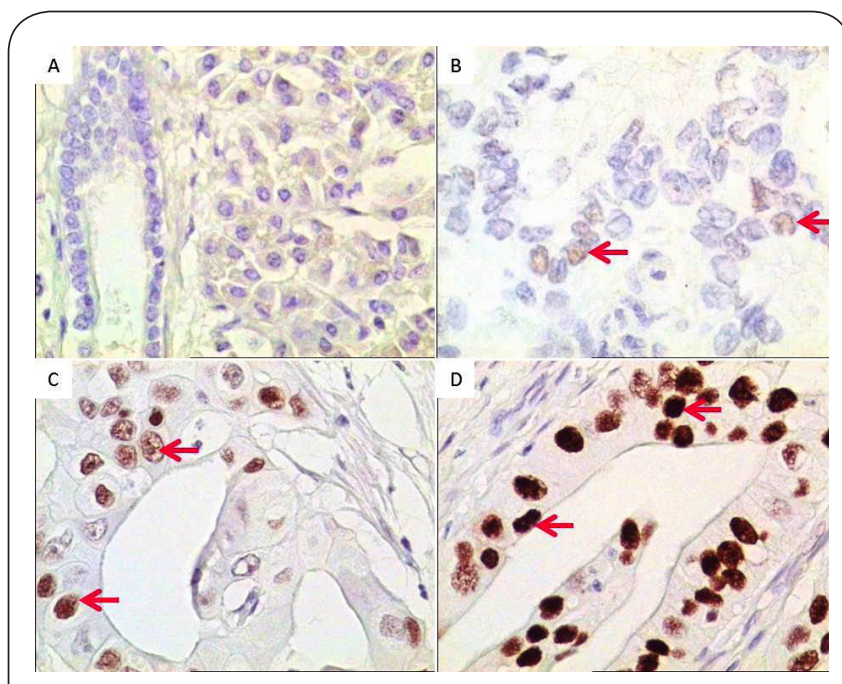

Figure 3. Immunohistochemical visualisation of p53. (A) Note the absence of $\mathrm{p} 53$ expression in the normal pancreatic duct. IP, OM 400x. (B) Weak nuclear expression of p53 in PDAC. IP, OM 400x. (C) Moderate nuclear expression of p53 in PDAC. IP, OM 400x. (D) Intense nuclear expression of p53 in PDAC. IP, OM 400x.

shown in Table 2, the tumours were mostly larger than 2 $\mathrm{cm}$ and localised in the pancreatic head. Perineural and intraneural invasion (Figure 1) was frequent as well as resection margin involvement by the tumour (Figure 1) and neoplastic invasion in or around blood vessels.

\section{Immunohistochemical findings}

The staining of Ki- 67 was localized to the nucleus of tumour cells (Figure 2). It was found on average in $20.2 \%$ (range $1-55 \% ; 95 \% \mathrm{Cl}=17.3-25.0$ ) of malignant cells. By t-test, no correlation was found between $\mathrm{Ki}-67$ and clinical and morphological parameters $(p>0.05)$.

Nuclear staining with p53 was detected in $35 / 50$ (70.0\%; $95 \% \mathrm{Cl}=56.2-80.9$ ) of all cases. Aberrant p53 expression was present in $37.5 \%$ (range $2-97 \% ; 95 \% \mathrm{Cl}=30.4-44.6$ ) of malignant cells. By independent samples t-test, trend to correlation $(p=0.053)$ was found between $p 53$ expression and peri- and intraneural invasion (Figure 3 ).

$\mathrm{BCl}-2$ expression was found in the cytoplasm of pancreatic ductal epithelium. There was no positive staining in any malignant cell $(0 / 44$ cases; $0 \% ; 95 \% \mathrm{Cl}=0-7.9)$ in contrast to positive expression in lymphocytes (Figure 4).

The staining results with vimentin were positive in 10/49 (20.4\%; $95 \% \mathrm{Cl}=11.5-33.7)$ cases. Vimentin expression was found in $35.3 \%$ (range $3-98 \% ; 95 \% \mathrm{Cl}=24.1-46.5$ ) of malignant cells (Figure 5). No significant correlation was found between vimentin expression and clinical and or morphological characteristics ( $p>0.05)$.

CD44 expression was observed in $42 / 49(85.7 \% ; 95 \% \mathrm{Cl}=$ 


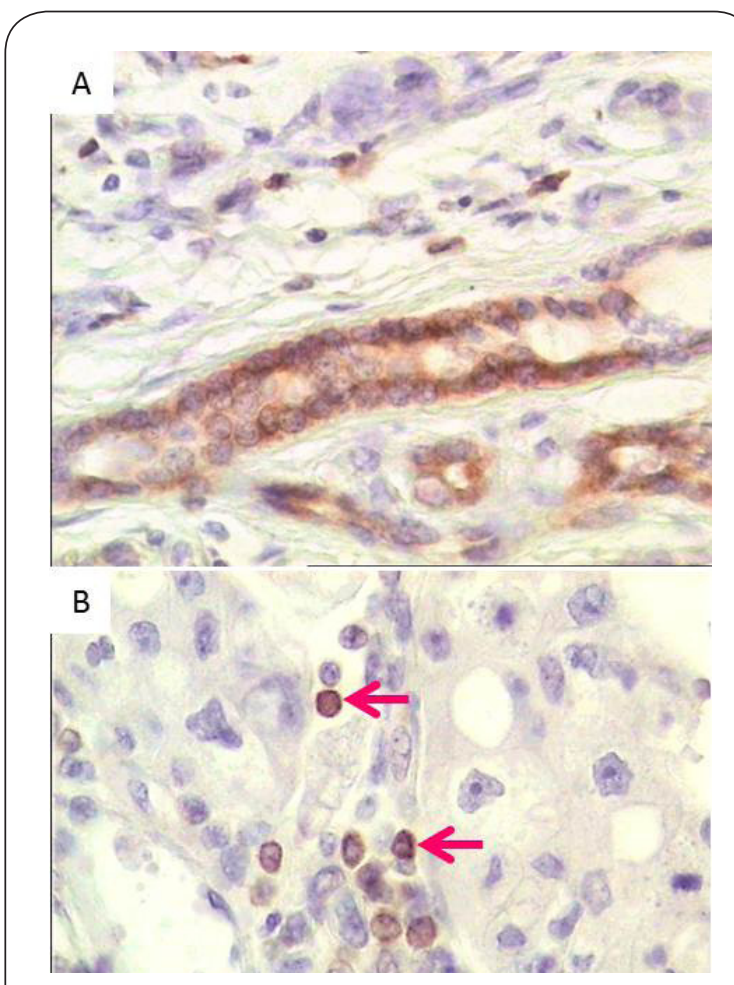

Figure 4. Immunohistochemical visualisation of Bcl-2 protein. (A) Cytoplasmic expression of Bcl-2 in pancreatic ductal epithelium and lymphocytes. IP, OM 400x. (B) Note the loss of Bcl-2 expression in PDAC, but positive expression in lymphocytes. IP, OM 400x.

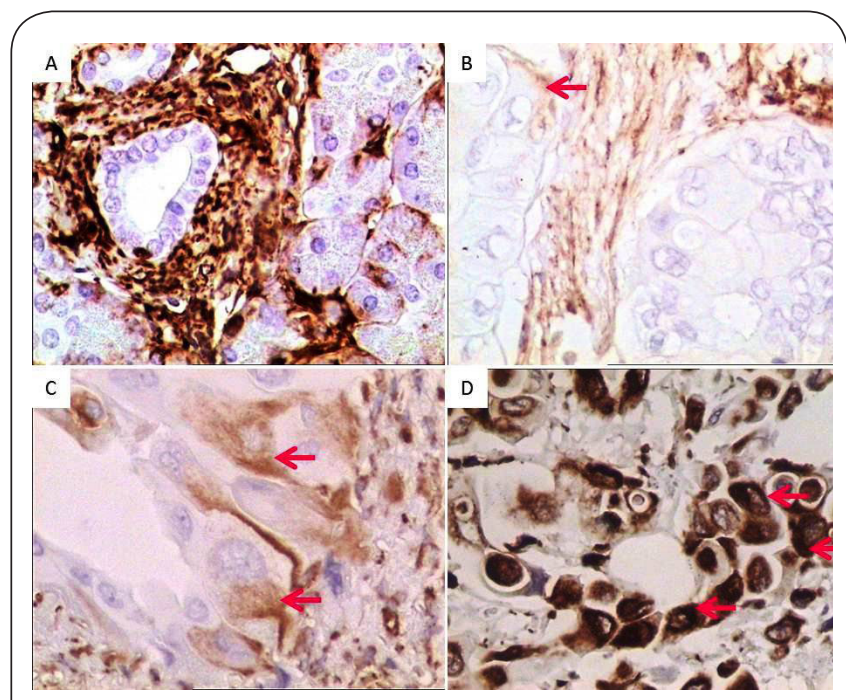

Figure 5. Immunohistochemical visualisation of vimentin. (A) Note the absence of vimentin expression in benign pancreatic ductal epithelium. IP, OM 400x. (B) Weak cytoplasmic expression of vimentin in PDAC. IP, OM 400x. (C) Moderate cytoplasmic expression of vimentin in PDAC. IP, OM 400x. (D) Intense cytoplasmic expression of vimentin in PDAC. IP, OM 400x

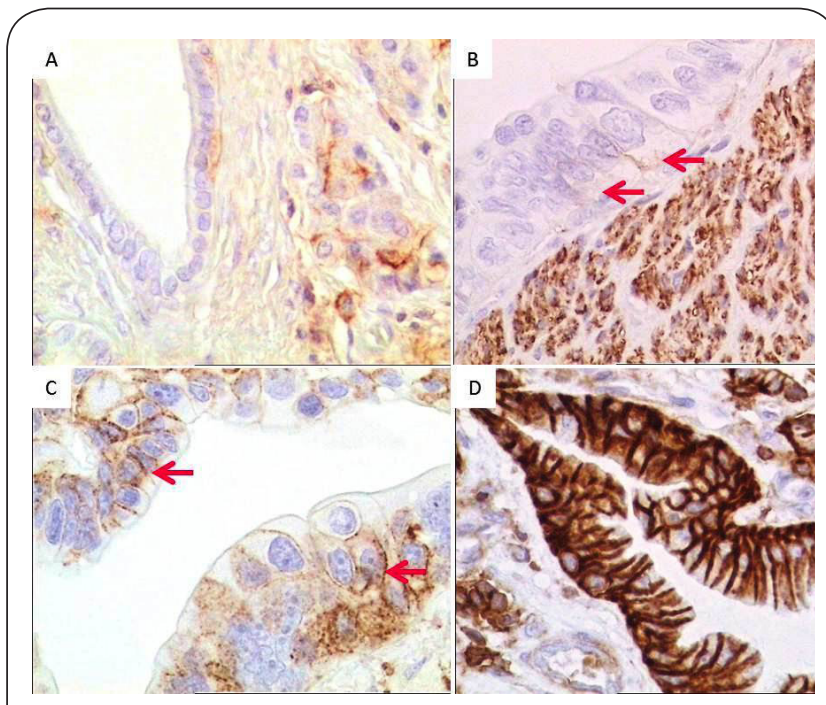

Figure 6. Immunohistochemical visualisation of CD44. (A) Weak basal membranous expression of CD44 in benign pancreatic ductal epithelium. IP, OM 400x. (B) Weak membranous expression of CD44 in PDAC. IP, OM 400x. (C) Moderate membranous expression of CD44 in PDAC. IP, OM 400x. (D) Intense membranous expression of CD44 in PDAC. IP, OM 400x.

73.3-92.8) cases. CD44 positivity was found in $28.2 \%$ (range $1-97 \% ; 95 \% \mathrm{Cl}=20.5-35.9$ ) of malignant cells (Figure 6). By using independent sample t-test, there was statistically significant association between CD44 expression and presence of metastases in regional lymph nodes $(p=$ 0.022). Positive correlation was found between CD44 and $\mathrm{Ki}-67(\mathrm{p}=0.010)$ as well as a trend to correlation between CD44 and vimentin expression ( $p=0.058$ ) by Spearman's rank correlation.

\section{Survival analysis}

The mean patients' survival was 19.5 month $(95 \% \mathrm{Cl}=$ 11.3-27.8) with 1- and 3-year survival rates of $41.8 \%(95 \%$ $\mathrm{Cl}=29.7-55.0)$ and $7.3 \%(95 \% \mathrm{Cl}=3.0-17.3)$. Survival curve by Kaplan-Meier analysis is shown in Figure 7. Survival for one patient was 99 months (till June 2012). It was a female patient age 68 years. The greatest diameter of tumour was $2.5 \mathrm{~cm}$. Cancer invaded peripancreatic fat tissue, but resection margins were free of tumour at extensive sampling. The tumour was characterised by moderate histologic grade, presence of mitoses, lymph node metastasis, and perineural invasion (Figure 8).

Tumour size, lymph node status, pathologic stage, tumour grade, surgical resection margin status, vascular and perivascular invasion, peri- and intraneural invasion, Ki-67, p53, Bcl-2, vimentin and CD44 expression were evaluated as possible factors affecting survival. When analyzing 
Simtniece et al. Journal of Cancer Therapeutics \& Research 2012, http://www.hoajonline.com/journals/pdf/2049-7962-1-27.pdf

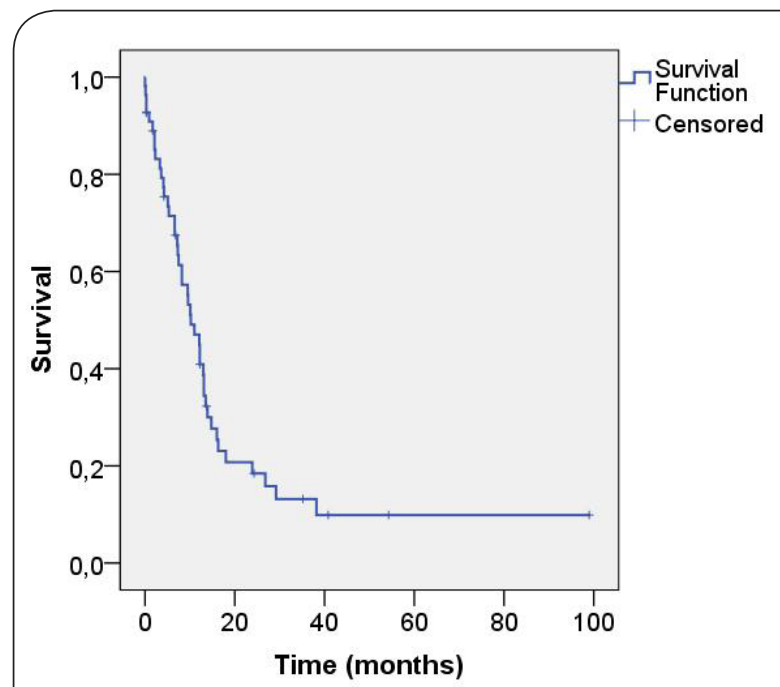

Figure 7. Survival for patients of pancreatic ductal adenocarcinoma after potentially radical surgical treatment. Kaplan-Meier survival analysis.

patients' survival with Spearman's rank correlation, positive correlation between poor prognosis and high proliferative activity by Ki-67 $(p=0.022)$ as well as vimentin expression $(p=0.023)$ was found. By independent samples t-test, the outcome correlated with tumour grade $(p=0.017)$ and positive surgical resection margins $(p=0.039)$. Log-rank test did not show correlation between SR and positive versus negative IHC staining. Cox regression analysis also yielded no association between SR and tumour stage, T, G, $\mathrm{N}, \mathrm{R}$ parameters and positive versus negative IHC staining. The other analyzed factors did not show any significant correlation with survival.

\section{Discussion}

Extensive studies have been made to explore prognostic and predictive factors of pancreatic carcinoma. As a result, several factors have been identified that convincingly correlate with a progression of the carcinoma, resistance to chemo- and radiotherapy and survival rate of patients. However, contradictory findings have been published regarding several parameters $[6,14,17]$. The aim of this study was to acquire comprehensive data of characteristic features of pancreatic carcinoma in the Latvian population, frequency of the known unfavourable prognostic factors, the extent of the immunohistochemical expression of several biologic markers and the impact of all the acquired parameters on the survival rate of the patients.

In our study the mean age of patients at the time of diagnosis was 63.2 years $(95 \% \mathrm{Cl}=60.5-65.9)$. This is in

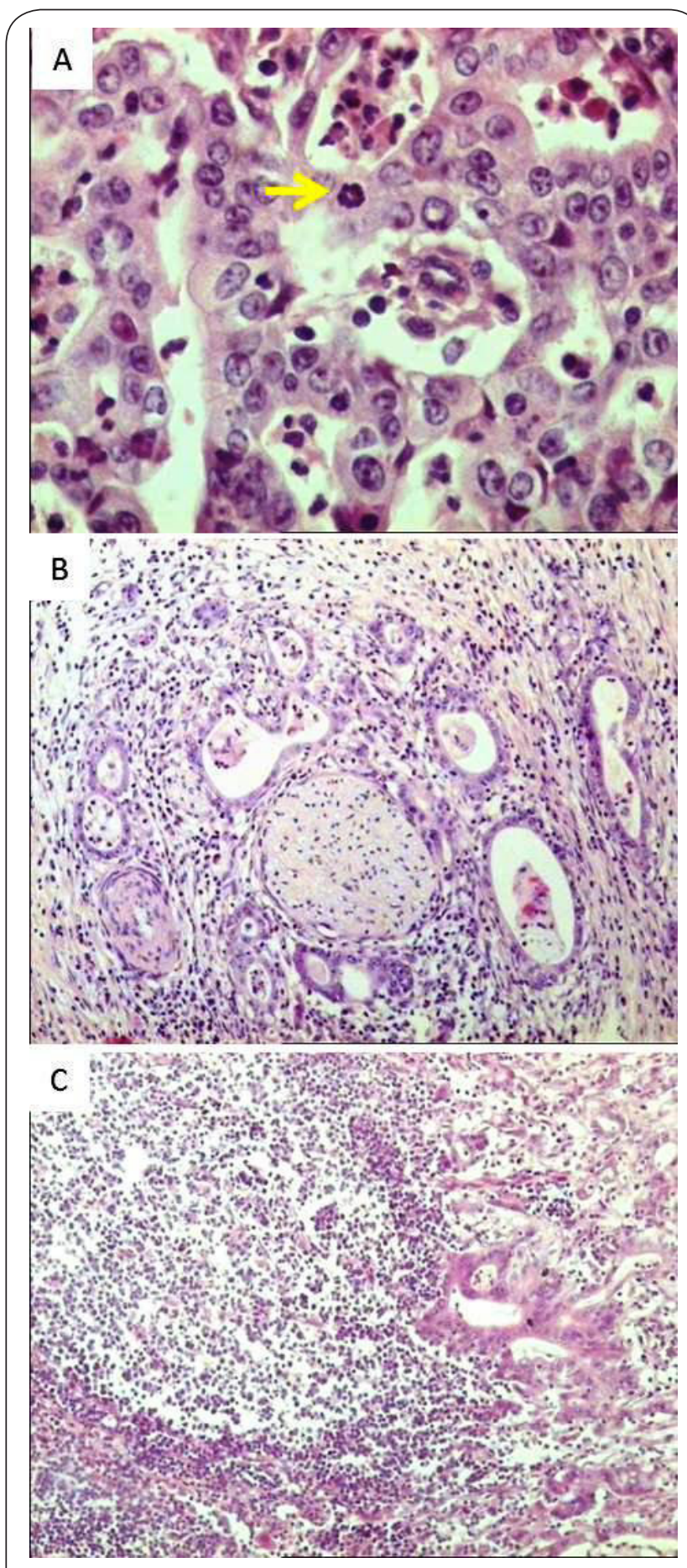

Figure 8. Pancreatic ductal adenocarcinoma of patient with 99 months survival. (A) PDAC with moderate histologic grade. Note the mitosis. HE, OM 400x. (B) PDAC showing perineural invasion. HE, OM 100x. (C) Lymph node metastasis of PDAC. HE, OM 100x. 
accordance with several other studies that have described the mean age of PDAC patients as 60.5 to 65 years $[15,24,25]$. Considering the $\mathrm{Cl}$, our study shows slight but statistically significant difference with the publication of Yang et al. where the mean age is 67 years [11]. The mean patients survival was 19.5 month $(95 \% \mathrm{Cl}=11.3-27.8)$ with 1 - and 3-year survival rates of $41.8 \%(95 \% \mathrm{Cl}=29.7-55.0)$ and $7.3 \%$ (95\% Cl $=3.0-17.3)$. In the study of An et al., the survival characteristics of surgically treated patients are similar: 12.2 month, 38\% and 10\%, respectively [15]. However, at least one study has detected statistically significantly different three year survival [12] that could be attributed to smaller tumour size and lower rate of metastases in regional lymph nodes. The differences could also be caused by genetic structure of the population as well as environmental and healthcare factors but in general our group reflects the problems in the treatment of pancreatic cancer and thus the results are applicable for the characteristics of this tumour in general.

Successful radical surgery is one of the most important prognostic factors in case of pancreatic carcinoma. The extent and type of surgery depends on the localization and spread of the cancer. Most frequently the tumour is localized in the head of pancreas therefore pancreatoduodenectomy is mostly necessary $[12,13,26]$. In our study it was performed in $85.7 \%(95 \% \mathrm{Cl}=75.0-92.2)$ cases, and total pancreatectomy was done in $6.4 \%(95 \% \mathrm{Cl}=2.6-15.2)$ cases. In another study pancreatoduodenectomy was performed in 335/356 (94.1\%) and a total pancreatectomy in 21/356 (5.9\%) of cases [13]. Thus, the surgical approach in our study also is comparable to the accepted practice. Significant correlation between the total pancreatectomy and shorter survival $(p=0.04)$ has also been described [13]. It should be taken into account that a total pancreatectomy is performed in cases when the tumour is multifocal or widely invasive and it is impossible to perform an anastomosis of pancreas due to risk of fistula. All these features are unfavourable characteristics of carcinoma. The general health status and thus the prognosis worsens after total pancreatectomy also due to exocrine and endocrine insufficiency, malabsorbtion, unmanageable level of glycemia and possible liver failure $[27,28]$.

The most frequently noted prognostic factors are tumour size, metastasis in lymph nodes, distal metastasis, high tumour grade and positive resection margins. Regarding tumour size by the largest diameter, two values have been described as prognostic threshold: $2 \mathrm{~cm}(p=0.02)$ and $3 \mathrm{~cm}(p=0.02)[12,13,26]$. In our study there was no correlation between the tumour size and survival. The size of tumour was larger than $2 \mathrm{~cm}$ in $90.9 \%(95 \% \mathrm{Cl}=$ 78.8-96.3) cases exceeding the frequency described by Lim et al. - 239/309 (77.3\%) cases as well as by Allema et al. - 98/176 (55\%) cases $[12,26]$. In our group, the tumour size exceeded $3 \mathrm{~cm}$ in $68.2 \%(95 \% \mathrm{Cl}=53.4-80.0)$ cases that also is statistically significantly more than in other studies, where it was $42 \%$ and $139 / 356$ (39.1\%), respectively $[13,25]$. There is a statistically significant difference in the $\mathrm{N} 1$ parameter between our data, namely, $67.2 \%(95 \% \mathrm{Cl}=$ 54.7-77.7) and other three studies - 37.0\%, 193/396 (48.7\%) and $80.0 \%[12,24,25]$. Although in our study we found no correlation between $\mathrm{N}$ stage and survival rate, in other studies presence of lymph node metastases is described as a significant factor ( $p=0.01$ or 0.05 ) that affects the survival $[12,13]$. It is likely that the generally large tumour size and high rate of regional lymph node metastases in our group embarrass the prognostic evaluation of these findings. Regarding the postsurgical survival correlation with tumour grade and resection margins, it was found that survival rate is worse in the group of patients with a high grade tumours $(p=0.017)$ and positive resection margins $(p=0.039)$. Similar results $(p=0.01 ; p=0.01)$ are described by Handra - Luca et al. [13].

The progression of pancreatic carcinoma and resistance to chemotherapy is thought to be associated with lack of apoptosis and adhesion, higher proliferation and epithelial-mesenchymal transition in neoplastic cells. To acknowledge the frequency and significance of each factor, the immunohistochemical staining was performed, detecting $\mathrm{Ki}-67, \mathrm{p} 53, \mathrm{Bcl}-2$, vimentin and CD44.

$\mathrm{Ki}-67$ is one of the most important markers that indicate active cellular proliferation. The highest expression of this protein is in $\mathrm{G}_{2}$ phase of proliferative cells. Expression is noted also in phases $G_{1}, S$ and $M$, but no expression is found in phase $G_{0}$ [29]. Ki-67 expression correlates with the tumour grade and lymph node metastasis [29]. It has also been stated that the expression of $\mathrm{Ki}-67$ becomes prognostically significant if it exceeds $5 \%[6,7]$. Our results show that the level of the Ki-67 expression is statistically significantly related to postoperative survival $(p=0.022)$, although there are some other studies that have not been able to demonstrate this correlation $[30,31]$.

p53 is a tumour suppressor protein. The corresponding gene is located in chromosome 17p. p53 protein participates in DNA reparation, as well as in the regulation of the cell cycle and apoptosis. P53 gene mutation is the most frequent known mutation in malignant tumours, found in about $50-75 \%$ cases of PDAC $[6,10]$. Expression of aberrant p53 has been noted also in $10 \%$ of cases of normal pancreatic tissue [32]. A rapid elevation of $\mathrm{p} 53$ positive cell count has been detected in the 3rd stage of pancreatic intraepithelial neoplasia, known also as carcinoma in situ. It follows that p53 is an early and important biological marker in the development and diagnosis of pancreatic carcinoma [33]. In our study p53 was found in $70 \%(95 \% \mathrm{Cl}=56.2-80.9)$ of cases. The results about the expression of p53 in the tumour cells and its correlation with a survival are contradictory $[6,14,34]$. In our study p53 expression showed trend to correlation with peri- and intraneural invasion $(p=0.053)$ 
but not with survival.

$\mathrm{BCl}-2$ is an anti-apoptotic protein that regulates apoptosis by mediating cytosolic release of cytochrome $C$ from mitochondria in response to cellular stress [35]. Although expression of $\mathrm{Bcl}-2$ is described in $12-67 \%$ of PDAC cases [14], no expression of $\mathrm{BCl}-2$ in malignant cells was identified in our study. The differences can be attributed to technological factors as incubation time and dilution of primary antibody. In our study, appropriate positive controls were used to ensure the quality of investigation. The presence of reactivity in lymphocytes and normal ductal epithelia is likely to exclude technological problems that theoretically could be related to prolonged storage of paraffin blocks. Expression of $\mathrm{BCl}-2$ in tumour cells has been noted as independent favourable prognostic factor and unfavourable predictive factor [14,36-38]. Resistance to chemotherapyinduced apoptosis is associated with over-expression of $\mathrm{BCl}-2$ in pancreatic cancer $[16,17]$. A positive correlation has been found between the $\mathrm{BCl}-2$ expression and tumour invasion and development of metastases [16,38].

Vimentin is an intermediate-size filament polypeptide that is expressed in normal mesenchymal tissues, but normally is absent in epithelium of pancreatic ducts. Expression of vimentin in cancer cells is one of the manifestations of epithelial-mesenchymal transition $[13,18,24]$. Expression of vimentin in PDAC cells is mentioned in about $45 \%$ of cases, that statistically significantly differs from our study, where the expression of vimentin was found in 20.4\% (95\% $\mathrm{Cl}=11.5-33.2)$ pancreatic carcinoma cases. In the study of Handra-Luca et al., a correlation between vimentin expression in tumour cells and worse survival $(p=0.02)$ was found similarly to our results $(p=0.023)$. A correlation of vimentin with a high grade, marked invasive growth and metastatic ability has also been described. However, in our study there was no significant relation between these factors. Similarly to $\mathrm{BCl}-2$, vimentin expression is related to the resistance to chemotherapy $[13,24,25]$.

CD44 is an integral cell surface glycoprotein and a type I transmembrane adhesion molecule. It mediates cell differentiation, migration and development of tumour metastases [20]. In our study CD44 was expressed in $85.7 \%$ $(95 \% \mathrm{Cl}=73.3-92.8)$ cases and these results statistically significantly differ from the study of Immervol et al. [19] describing lower expression rate of $67 \%$. Expression of CD44 is related to worse prognosis, but the published results are not unequivocal [19]. In our study no correlation was found between CD44 and survival, but there was a correlation between CD44 and N stage $(p=0.022)$, proliferative activity $(p=0.010)$. Trend to correlation between CD44 and vimentin expression $(p=0.058)$ was found. The latter two parameters also correlated with the survival of patients. Other studies show that CD44 expression correlates also with tumour invasion and epithelial mesenchymal transition $[20,39]$.

In general, the survival analysis discloses significant problems in the treatment of pancreatic carcinoma. The identified biologic markers could become an important target for future therapeutic intervention if expressed with significant frequency as CD44 and p53 and associated with important characteristics of neoplastic process as proliferation and development of metastases. However, the constellation of the observed proliferative activity level and high frequency of markers known for the association with resistance to chemotherapy also point towards significant role of surgery in the present treatment of pancreatic carcinoma.

\section{Conclusions}

1. In case of pancreatic ductal adenocarcinoma, the survival after potentially curative resection is poor, with the mean value of 19.5 month. However, the constellation of tumour biological properties still points towards the crucial role of surgery in the treatment of pancreatic ductal adenocarcinoma.

2. High tumour grade, positive resection margins, high proliferation fraction and epithelial-mesenchymal transition negatively affect patients' survival.

3. CD44 expression is frequent finding in pancreatic ductal adenocarcinoma, occurring in $85.7 \%$ of cases. It correlates with basic features of neoplastic process as proliferation (by Ki-67) and metastatic spread to regional lymph nodes. This biological marker could be considered as a therapeutic target in the future.

4. The frequently observed expression of aberrant p53 protein trends to correlate with perineural and intraneural invasion.

\section{Competing interests}

The authors declare that they have no competing interests.

\section{Authors' contribution}

All authors participated in the design of the study. ZS carried out the archive search. ZS, IS, AA performed the re-evaluation of surgical slides to reach consensus estimate of morphological data. AV re-evaluated the clinical data. ZS performed immunohistochemical stains. ZS, IS and AA evaluated the immunohistochemical data in order to reach consensus statement. AA assisted with survival data obtaining and analysis. ZS and AV were responsible for statistical analysis. ZS, IS and AV performed the literature studies. ZS wrote the draft; IS and JG improved the manuscript. All authors read and approved the final manuscript.

\section{Acknowledgements}

This work was supported by The National Research Programme "Development of new prevention, treatment, diagnostics means and practices and biomedicine technologies for improvement of public health".

Publication history

Received: 14-July-2012 Revised: 07-Sep-2012

Accepted: 24-Sep-2012 Published: 13-Oct-2012 


\section{References}

1. Ferlay J, Shin HR, Bray F, Forman D, Mathers C, Parkin DM: Estimates of worldwide burden of cancer in 2008: GLOBOCAN 2008. Int J Cancer 2010, 127:2893-2917. | Article | PubMed

2. Bilimoria KY, Bentrem DJ, Ko CY, Ritchey J, Stewart AK, Winchester DP, Talamonti MS: Validation of the 6th edition AJCC Pancreatic Cancer Staging System: report from the National Cancer Database. Cancer 2007, 110:738-744. | Article | PubMed

3. Carpelan-Holmstrom M, Nordling S, Pukkala E, Sankila R, Luttges J, Kloppel G, Haglund C: Does anyone survive pancreatic ductal adenocarcinoma? A nationwide study re-evaluating the data of the Finnish Cancer Registry. Gut 2005, 54:385-387. | Article I PubMed Abstract | PubMed Full Text

4. Takaori K, Hruban RH, Maitra A, Tanigawa N: Pancreatic intraepithelial neoplasia. Pancreas 2004, 28:257-262. | Article | PubMed

5. Cleary SP, Gryfe R, Guindi M, Greig P, Smith L, Mackenzie R, Strasberg S, Hanna S, Taylor B, Langer B, Gallinger S: Prognostic factors in resected pancreatic adenocarcinoma: analysis of actual 5-year survivors. J Am Coll Surg 2004, 198:722-731. | Article | PubMed

6. Ansari D, Rosendahl A, Elebro J, Andersson R: Systematic review of immunohistochemical biomarkers to identify prognostic subgroups of patients with pancreatic cancer. Br J Surg 2011, 98:1041-1055. | Article I PubMed

7. Jamieson NB, Carter CR, McKay CJ, Oien KA: Tissue biomarkers for prognosis in pancreatic ductal adenocarcinoma: a systematic review and meta-analysis. Clin Cancer Res 2011, 17:3316-3331. | Article | PubMed

8. Simtniece Z, Vanags A, Strumfa I, Pavars M, Gardovskis J: Prognostic factors in potentially radically operated pancreatic carcinoma. Acta Chirurgica Latviensis 2011, 11:34-38. I Article

9. Niederhuber JE, Brennan MF, Menck HR: The National Cancer Data Base report on pancreatic cancer. Cancer 1995, 76:1671-1677. | PubMed

10. Yeo TP, Hruban RH, Leach SD, Wilentz RE, Sohn TA, Kern SE, lacobuzioDonahue CA, Maitra A, Goggins M, Canto MI, Abrams RA, Laheru D, Jaffee EM, Hidalgo M, Yeo CJ: Pancreatic cancer. Curr Probl Cancer 2002, 26:176-275. | Article | PubMed

11. Yang R, Cheung MC, Byrne MM, Jin X, Montero AJ, Jones C, Koniaris LG: Survival effects of adjuvant chemoradiotherapy after resection for pancreatic carcinoma. Arch Surg 2010, 145:49-56. | Article | PubMed

12. Lim JE, Chien MW, Earle CC: Prognostic factors following curative resection for pancreatic adenocarcinoma: a population-based, linked database analysis of 396 patients. Ann Surg 2003, 237:74-85. | Article | PubMed Abstract | PubMed Full Text

13. Handra-Luca A, Hong SM, Walter K, Wolfgang C, Hruban R, Goggins M: Tumour epithelial vimentin expression and outcome of pancreatic ductal adenocarcinomas. Br J Cancer 2011, 104:1296-1302. | Article | PubMed Abstract | PubMed Full Text

14. Smith RA, Tang J, Tudur-Smith C, Neoptolemos JP, Ghaneh P: Metaanalysis of immunohistochemical prognostic markers in resected pancreatic cancer. Br J Cancer 2011, 104:1440-1451. | Article | PubMed Abstract | PubMed Full Text

15. An W, Ben QW, Chen HT, Zheng JM, Huang L, Li GX, Li ZS: Low Expression of IGFBP7 is Associated with Poor Outcome of Pancreatic Ductal Adenocarcinoma. Ann Surg Oncol 2012. I Article I PubMed

16. Galante JM, Mortenson MM, Bowles TL, Virudachalam S, Bold RJ: ERK/BCL-2 pathway in the resistance of pancreatic cancer to anoikis. J Surg Res 2009, 152:18-25. | Article | PubMed

17. Dong J, Zhao YP, Zhou L, Zhang TP, Chen G: Bcl-2 upregulation induced by miR-21 via a direct interaction is associated with apoptosis and chemoresistance in MIA PaCa-2 pancreatic cancer cells. Arch Med Res 2011, 42:8-14. I Article I PubMed

18. Thiery JP, Sleeman JP: Complex networks orchestrate epithelialmesenchymal transitions. Nat Rev Mol Cell Biol 2006, 7:131-142. | Article | PubMed

19. Immervoll H, Hoem D, Steffensen OJ, Miletic H, Molven A:
Visualization of CD44 and CD133 in normal pancreas and pancreatic ductal adenocarcinomas: non-overlapping membrane expression in cell populations positive for both markers. J Histochem Cytochem 2011, 59:441-455. | $\underline{\text { Article | PubMed Abstract | PubMed Full Text }}$

20. Ringel J, Jesnowski R, Schmidt C, Kohler HJ, Rychly J, Batra SK, Lohr M: CD44 in normal human pancreas and pancreatic carcinoma cell lines. Teratog Carcinog Mutagen 2001, 21:97-106. | Articlel PubMed

21. Klöppel G, Hruban RH, Longnecker DS, Adler G, Kern SE: Tumours of the Exocrine Pancreas. In: World Health Organization Classification of Tumours. Pathology and Genetics of Tumours of the Digestive System. Edited by Hamilton S, Aaltonen LA. Lyon, IARC 2000, 219-230. | Pdf

22. Edge SB, Byrd DR, Compton CC, Fritz AG, Greenc FL: Exocrine and Endocrine Pancreas. In: AJCC Cancer Staging Handbook. 7th ed. 2010, 285-296. | Book

23. Altman D, Machin D, Bryant T, Gardner S: Statistics with confidence: confidence interval and statistical guidelines, $2^{\text {nd }}$ edition. Bristol, BMJ Books 2000.

24. Ruckert F, Aust D, Bohme I, Werner K, Brandt A, Diamandis EP, Krautz C, Hering S, Saeger HD, Grutzmann R, Pilarsky C: Five primary human pancreatic adenocarcinoma cell lines established by the outgrowth method. J Surg Res 2012, 172:29-39. | Article | PubMed

25. Masugi Y, Yamazaki K, Hibi T, Aiura K, Kitagawa Y, Sakamoto M: Solitary cell infiltration is a novel indicator of poor prognosis and epithelialmesenchymal transition in pancreatic cancer. Hum Pathol 2010, 41:1061-1068. | Article| PubMed

26. Allema JH, Reinders ME, van Gulik TM, Koelemay MJ, Van Leeuwen DJ, de Wit LT, Gouma DJ, Obertop H: Prognostic factors for survival after pancreaticoduodenectomy for patients with carcinoma of the pancreatic head region. Cancer 1995, 75:2069-2076. | Article | PubMed

27. Heidt DG, Burant C, Simeone DM: Total pancreatectomy: indications, operative technique, and postoperative sequelae. J Gastrointest Surg 2007, 11:209-216. | Article| PubMed

28. Kulu Y, Schmied BM, Werner J, Muselli P, Buchler MW, Schmidt J: Total pancreatectomy for pancreatic cancer: indications and operative technique. HPB (Oxford) 2009, 11:469-475. | Article| PubMed Abstract | PubMed Full Text

29. Hu HY, Liu H, Zhang JW, Hu K, Lin Y: Clinical Significance of Smac and Ki-67 Expression in Pancreatic Cancer. Hepatogastroenterology 2012 59: | PubMed

30. Stanton KJ, Sidner RA, Miller GA, Cummings OW, Schmidt CM, Howard TJ, Wiebke EA: Analysis of Ki-67 antigen expression, DNA proliferative fraction, and survival in resected cancer of the pancreas. Am J Surg 2003, 186:486-492. | Article| PubMed

31. Gansauge F, Gansauge S, Schmidt E, Muller J, Beger HG: Prognostic significance of molecular alterations in human pancreatic carcinoma-an immunohistological study. Langenbecks Arch Surg 1998, 383:152-155. | Article| PubMed

32. Liu H, Shi J, Anandan V, Wang HL, Diehl D, Blansfield J, Gerhard G, Lin $\mathrm{F}$ : Reevaluation and identification of the best immunohistochemical panel (pVHL, Maspin, S100P, IMP-3) for ductal adenocarcinoma of the pancreas. Arch Pathol Lab Med 2012, 136:601-609. | Article | PubMed

33. Takaori K Hruban RH, Maitra A, Tanjigawa N: Current topicsson pubcyred

34. Linder S, Parrado C, Falkmer UG, Blasjo M, Sundelin P, von Rosen A: Prognostic significance of $\mathrm{Ki}-67$ antigen and $\mathrm{p} 53$ protein expression in pancreatic duct carcinoma: a study of the monoclonal antibodies MIB-1 and DO-7 in formalin-fixed paraffin-embedded tumour material. Br J Cancer 1997, 76:54-59. I PubMed Abstract | PubMed Full Text

35. Hamacher R, Schmid RM, Saur D, Schneider G: Apoptotic pathways in pancreatic ductal adenocarcinoma. Mol Cancer 2008, 7:64. | Article | PubMed Abstract | PubMed Full Text

36. Nio Y, Dong M, Iguchi C, Yamasawa K, Toga T, Itakura M, Tamura K: 
Simtniece et al. Journal of Cancer Therapeutics \& Research 2012, http://www.hoajonline.com/journals/pdf/2049-7962-1-27.pdf

Expression of $\mathrm{Bcl}-2$ and $\mathrm{p} 53$ protein in resectable invasive ductal carcinoma of the pancreas: effects on clinical outcome and efficacy of adjuvant chemotherapy. J Surg Oncol 2001, 76:188-196. | Article I PubMed

37. Dong M, Zhou JP, Zhang H, Guo KJ, Tian YL, Dong YT:

Clinicopathological significance of $\mathrm{Bcl}-2$ and Bax protein expression in human pancreatic cancer. World J Gastroenterol 2005, 11:27442747. I Article I PubMed

38. ShengMian L, YiJuan W, XiaoChen W, XiaoLing W: Expression of Smac, Bcl-2 and Ki-67 in pancreatic carcinoma and its prognostic significance. Tumor 2009, 29: 1076-1081. | Article

39. Zhang Y, Wei J, Wang H, Xue X, An Y, Tang D, Yuan Z, Wang F, Wu J, Zhang J, Miao Y: Epithelial mesenchymal transition correlates with CD24+CD44+ and CD133+ cells in pancreatic cancer. Oncol Rep 2012, 27:1599-1605. | Article| PubMed

\section{Citation:}

Strumfa I, Simtniece Z, Abolins A, Vanags A and Gardovskis J: Prognostic Factors after Curative

Resection of Pancreatic Ductal Adenocarcinoma: a Retrospective Study. journal of Cancer Therapeutics and Research 2012, 1:27.

http://dx.doi.org/10.7243/2049-7962-1-27 